\title{
Procurement 4.0: How the digital disruption supports cost-reduction in Procurement
}

\author{
Timo Klünder" (D), Jan Niklas Dörseln ${ }^{\mathrm{a}}$ (D), Marion Steven ${ }^{\mathrm{a}}$

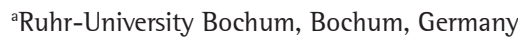 \\ *timo.kluender@rub.de
}

\begin{abstract}
Paper aims: "Without purchasing, Industry 4.0 will not take place". Procurement ensures supplies at the lowest level of costs. Those costs account for more than 50\% of the gross production value. This paper analyses, explains and proves that digitization reduces cost even further.

Originality: This empirical examination as well as the explanatory approach are key supplements to previous survey-based studies on the effect of digitization on procurement costs.

Research method: The digitized procurement process and the application of technologies were analysed in detail by establishing a Procurement 4.0-Framework in order to prove evidence of digitally induced cost-cutting effects. The hypothesis that the use of Industry 4.0-Technologies leads to cost reductions is empirically tested with data by the federal statistical office. The Pearson correlation coefficient measures the strength of correlation between the degree of technology usage and costs of material and commodities. The correlations are empirically tested using a t-test.
\end{abstract}

Main findings: The correlations' strength between digitization and the development of procurement costs enables to confirm the hypothesis and allows an in-depth analysis of technology-specific effects based on a Procurement 4.0-Framework.

Implications for theory and practice: This paper effectively supports the implementation of technologies for the reduction of costs.

\section{Keywords}

Industry 4.0. Procurement 4.0. Digitization. Procurement costs.

How to cite this article: Klünder, T., Dörseln, J. N., \& Steven, M. (2019). Procurement 4.0: How the digital disruption supports cost-reduction in Procurement. Production, 28, e20180104. https://doi.org/10.1590/0103-6513.20180104

Received: Dec. 7, 2018; Accepted: Apr. 20, 2019.

\section{Introduction}

Industry 4.0 does not only take place in a smart factory but also and especially in procurement (Glas \& Kleemann, 2016). Industry 4.0 represents the overlapping of different technological developments that support and enhance products and processes (Schmidt et al., 2015). A main driver of its implementation is an expected cost reduction (PricewaterhouseCoopers, 2014). Digitization is expected to minimize the usage of material (Lasi et al., 2014). Since a minimization of material usage leads to a cost reduction, a direct link between procurement costs and industry 4.0 exists.

Numerous studies on the effect of Industry 4.0 on production have been published so far (e.g. PricewaterhouseCoopers, 2014; Kagermann, 2015). Yet, there is a discrepancy between the goal of cost reduction through digitization and an insufficient consideration of procurement in previous studies. Procurement is the main cost driver for the organization (Foster \& Gupta, 1990; Krampf, 2014). Depending on the branch, the costs of material often exceed 50\% of the gross production value. Companies in the automotive sector even spend up to $80 \%$ of the gross production value on their production factors (Daimler AG, 2016). 
Cost reductions in the procurement process can have a disproportionately high effect on the organization's profit (leverage effect) (Möllering et al., 2005). For example, a reduction of the material costs could correspond to an overproportional increase in revenue. Both leads to the same increase of the return on investment (Arnolds et al., 2013). Thus, only the evidence of a connection between digitization efforts and cost changes justifies a deeper investigation of the effects of new technologies on procurement costs.

The paper proposes a combination of two interdependent questions:

1) Does an interrelation between the development of procurement costs and the implementation of digital technologies exist?

2) How to explain the identified relations?

For this purpose the procurement process and the technologies of industry 4.0 are presented and linked with each other to a proprietary Procurement 4.0-Framework. Then the theoretical connection is empirically tested. Afterwards hypotheses for the discovered interrelations are formulated with reference to the initially introduced procurement process. The paper concludes with a summary of key findings and an outlook.

\section{Procurement}

Industry 4.0 is a widespread transition process that also leads to a profound change in procurement. The fourth industrial revolution is introduced and the main task of procurement 4.0 outlined (sub-section 2.1). The examination of the cost structure is necessary to determine the digitization's effects on procurement costs (sub-section 2.2). In order to ensure a structured and systematic approach, the procurement process is presented in sub-section 2.3, which then serves as the golden thread of all following analyses. Sub-section 2.4 uses this procurement process to derive the resulting cost elements.

\subsection{The objective of procurement in the shadow of industry 4.0}

Procurement represents a major function of business. It is responsible for ensuring the functionality of all processes by providing every good the company needs but does not produce itself (Theisen, 1974). Supported by the growing percentage of a globally outsourced production, procurement additionally focuses on providing the goods at the lowest possible costs. Therefore, procurement refers to all company- and/or market related activities aimed at providing a company with the required but not self-produced objects (Arnold, 1997). The function of procurement is subject to a disruptive change as a result of the fourth industrial revolution.

The term industry 4.0 was introduced by the acatech research union set up by the Federal Ministry of Education and Research (Kagermann et al., 2012). The Research Union called the associated disruptive transformation process as fourth industrial revolution in 2011. The fourth industrial revolution thus differs from the previous ones in that it was proclaimed prior to its realization. Following this proclamation, procurement is currently part of a revolutionary process.

By definition, an industrial revolution occurs when new technologies lead to a profound and lasting change in society and production technology. The first industrial revolution describes the transition from handcraft production to industrial production in factories. The use of electrical energy in conjunction with mass production based on the division of labour led to industrial mass production at the beginning of the 20th century. These developments are seen as the second industrial revolution. Automation as a result of advances in information technology in the second half of the 20th century triggered the third industrial revolution (Bauer et al., 2014).

Thus, an industrial revolution is characterized by changes on the organizational level, which are achieved by the widespread use of new technologies. Industry 4.0 should therefore also be explained via an organizational and a technological component (Steven \& Klünder, 2018; Drath, 2014):

- On the organizational level, industry 4.0 is characterized by a horizontal and vertical integration of companies that enable an individualized, sustainable, flexible and resilient production across companies in a decentralized and self-organizing supply chain, through which leaps in time, costs and quality can be achieved;

- These organizational changes in the value creation process are technologically driven by the networked use of real-time cyber-physical systems in the Internet of Things and Services, resulting in digitally integrated, autonomous Smart Factories. 
This paper also adopts that logic. Based on technological changes, organizational change processes are described that can potentially lead to cost reductions in procurement.

As already mentioned, industry 4.0 initially revolutionizes the production. Due to the major role of procurement - securing the production by providing all necessary goods - the ideas of industry 4.0 can be transferred to procurement.

Based on the idea that industry 4.0 characterizes the growing digital connection of the industrial production, which leads to entirely intelligent, connected and autonomous factories, procurement 4.0 represents two associated aspects (Kiel et al., 2017). On the operational level procurement 4.0 represents the intelligent determination of requirements and the autonomous procurement processing while promoting the cooperation to suppliers and the availability of all relevant information on the strategic level.

\subsection{Cost structure}

Procurement is responsible for obtaining any factors a company needs for its production but is unable to produce due to different reasons. Those factors include goods, services and even information, capital or personnel (Kummer et al., 2013). On the one hand goods comprise raw materials, (semi-) manufactured products, auxiliary and process materials that were aggregated as material. These are further processed by the procuring organization (Federal Statistical Office, 2018). Commodities on the other hand are goods of foreign origin that are resold unprocessed and with no connection to the own production process (Federal Statistical Office, 2018).

Table 1 shows the distribution of procurement costs in 2015 for different branches in Germany. The branches have been selected based on two factors. Firstly, because of their high relevance in the field of Industry 4.0. Secondly, they account for a significant share of GDP (Federal Statistical Office, 2018). The values in Table 1 are given as percentage of the gross production value. It is obvious that procurement costs with an average of 52\% are responsible for the major share of the gross production value and therefore the overall costs. It is important to consider the intersectoral and intertemporal differences. Therefore, a sectoral as well as temporal analysis is applied below.

Table 1. Procurement Costs of different Branches by share of GPV (Federal Statistical Office, 2018).

\begin{tabular}{|c|c|c|c|}
\hline \multirow{2}{*}{ Branch } & \multicolumn{3}{|c|}{ Type of Cost } \\
\hline & Costs of Material & Costs of Commodities & Overall Procurement Costs \\
\hline Chemical Goods & $38.1 \%$ & $18.3 \%$ & $56.4 \%$ \\
\hline Pharmaceutical Products & $24 \%$ & $13.6 \%$ & $37.6 \%$ \\
\hline Rubber and Plastic Goods & $43.1 \%$ & $10 \%$ & $53.1 \%$ \\
\hline Metal Production and Processing & $63.3 \%$ & $3.6 \%$ & $66.9 \%$ \\
\hline Fabricated Metal Products & $38.1 \%$ & $4.4 \%$ & $42.5 \%$ \\
\hline Electrical Equipment & $38.8 \%$ & $12.8 \%$ & $51.6 \%$ \\
\hline Mechanical Engineering & $41.5 \%$ & $9 \%$ & $50.5 \%$ \\
\hline Motor Vehicles and Components & $48.7 \%$ & $20.1 \%$ & $68.8 \%$ \\
\hline Other Transport Equipments & $50.9 \%$ & $1.4 \%$ & $52.3 \%$ \\
\hline Other Goods & $27.6 \%$ & $13.4 \%$ & $41 \%$ \\
\hline
\end{tabular}

Figure 1 illustrates the intensity of procured material, commodities or of the combination of both for selected branches over the period of eight years. Each of the intensities represent the costs relative to the revenue. In general, the development can be described as a negative trend since 2011, the year where the term "Industry 4.0" has been introduced by the german government (Bauer et al., 2014; Botthof, 2015). The average growth rate of the procurement cost / profit-relation is $0.01 \%$ and $-2.06 \%$ for the years 2011 to 2015 . This - mostly negative - trend is mainly caused by the development of the material intensity. Here, the average growth rate is between $-1.26 \%$ and $-2.51 \%$ which shows that the costs for material decreased per unit of revenue.

Even though the growth rates for the commodity intensity vary a little more and are, among others, positive $(7.85 \%$ and $-8.96 \%)$ the result of mostly negative growth rates is a first indicator that digitization leads to a decrease of procurement costs. Therefore, it supports the procurement's operational goal of minimizing the costs (Federal Statistical Office, 2018; own calculations). 


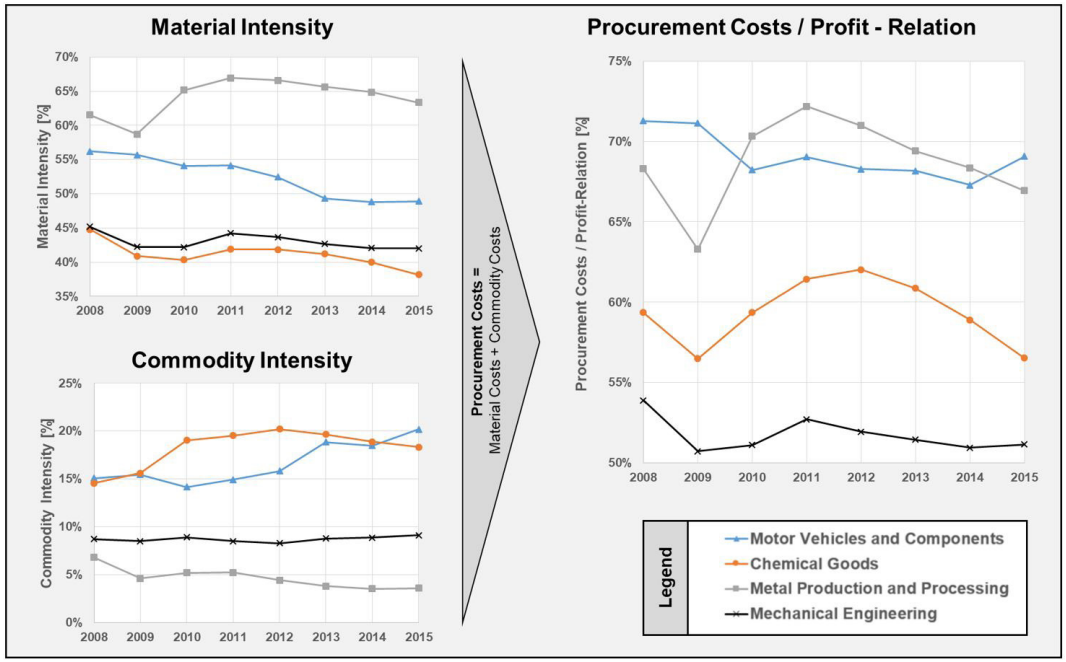

Figure 1. Cost Development in different Branches depending on Revenue (Federal Statistical Office, 2018).

\subsection{Procurement process}

The focus on material and commodities already implies through its definition that the following procurement tasks are oriented on the process of recurring procurement activities (Aisbett et al., 2005; Lee et al., 1997). Strategic procurement sets the framework for any supply activities of the enterprise and spans the possible scope of action. By determining the supplier portfolio the procuring organization defines its procurement strategy that specifies which suppliers meet the requirements in order to deliver the goods. The goods, that need to be procured, depend on the organization's category management. These decisions are supported by market research activities that gather, prepare and analyse all necessary information. The objective of strategic procurement is to secure the flexibility and independence of a company on the procurement market (Grochla \& Schönbohm, 1980; Melzer-Ridinger, 2008; Steven, 2013).

Within this possible scope of action, decisions have to be made in order to secure the supply for the next period (tactical procurement). Based on demand planning and the purchase requisition, offers of possible suppliers out of the portfolio need to be requested, evaluated and possibly negotiated with the preferred supplier. The tactical procurement phase ends with the supply agreement between the organization and the selected suppliers (Hütter, 2007).

Operational procurement describes the final execution of the selected procurement option. After the optimal order quantity has been determined, the order is placed either through a message to the supplier or automatic execution. Finally, the transportation of the ordered goods needs to be monitored until their arrival in the warehouse (Arnolds et al., 2013; Krampf, 2014).

The main objective of tactical and operative procurement is to minimize all costs arising in the procurement process. Procurement 4.0 supports this objective by automating these procurement activities.

\subsection{Cost elements in the procurement process}

The outlined procurement process results in five cost elements that determine the procurement costs (Hütter, 2007).

a. Demand Analysis Costs (DAC) include all costs that arise during strategic procurement activities. Besides the costs for the demand analysis (DA), depending on the planning horizon (PH), they especially contain costs for the planning capacity (PCC) which depend on the variety and complexity of material (M).

$$
D A C=P C C(M)+D A(P H)
$$

b. The Supplier Selection Costs (SSC) include personnel costs incurred for soliciting and comparing offers. They increase with the number of suppliers (S) consulted and the variety and complexity of the material (M) to be purchased.

$$
\operatorname{SSC}=\operatorname{SSC}(S, M)
$$


c. The Direct Procurement Costs (DPC) are similar to the SSC as they also depend on the number of suppliers but in the opposite way. As the number of suppliers $(\mathrm{S})$ increases, the competition between them rises and leads to lower purchase prices (p). Therefore, the DPC are the product of $\mathrm{p}$ and the demand of the period considered (d).

$$
D P C=D P C(S)=p(S) \cdot d
$$

d. Supplier Failure Recovery Costs (SFC) represent costs that arise for a renewed solicitation of one offer (SSC(1, M)) to avoid a shortfall situation. These costs only apply in case of a supplier failure whose probability of occurrence is represented by $\mathrm{f}(\mathrm{S})$. The probability of occurrence decreases with an increasing $\mathrm{S}$ in the supplier portfolio.

$$
S F C=\operatorname{SSC}(1, M) \cdot f(S)
$$

e. In accordance with the economic order quantity model by Harris, Order Costs (OC) consist of two components: costs of placing an order $(\mathrm{k})$ and holding costs for the storage of goods (h). This leads to OC per period (Andriolo et al., 2014):

$$
O C=\sqrt{2 \cdot k \cdot h \cdot d}
$$

\section{The digitization of procurement}

Individualization, shortened product lifecycles and technological innovations are met by the new production paradigm industry 4.0 (Koehler et al., 2015). It comprises product and process innovations due to the overlay of several technological developments (Schmidt et al., 2015). Before assigning the technologies to each production step (sub-section 3.2) these technologies will be presented (sub-section 3.1).

\subsection{Technologies}

Procurement is a distinctive and value-creating process that is changed by the industrial revolution. Therefore, Procurement 4.0 connects the organization with its suppliers and enables a dynamic cooperation and coordination of the procurement process (Glas \& Kleemann, 2016). Procurement 4.0 is substantially characterized by four technological areas (Figure 2):

Connectivity \& Communication:

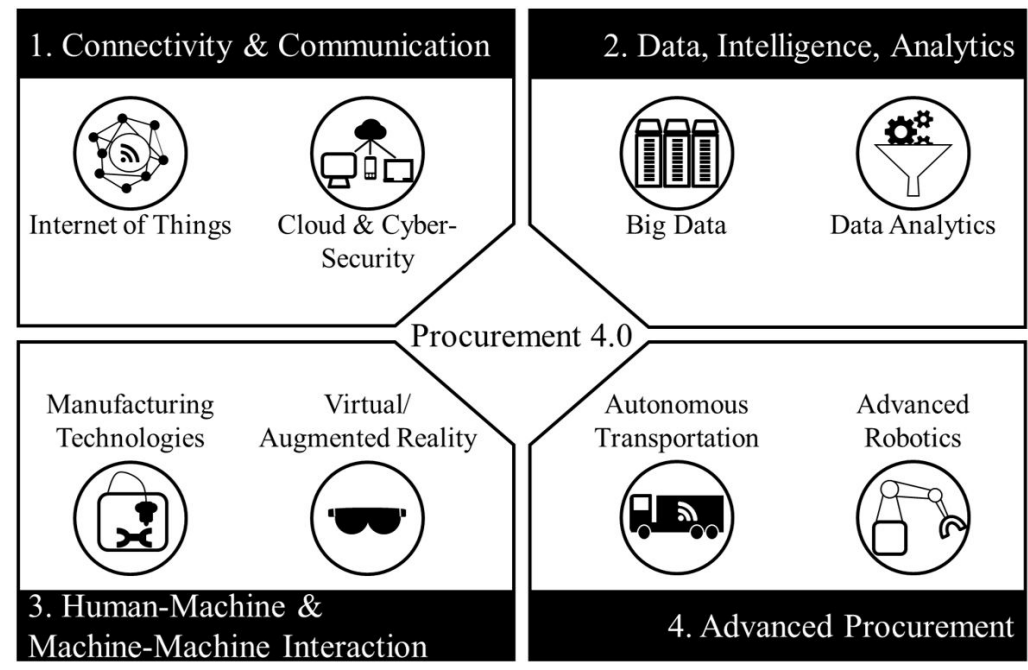

Figure 2. Technology Areas of Procurement 4.0 (Fostec, 2018). 
- Industrial Internet of Things: Embedding of heterogeneous devices from different participants with diverse functionalities into one network (Kovatsch et al., 2012);

- Cloud \& Cybersecurity: Management of large amounts of data in cloud-based, open, but secure systems in order to provide a universal data access (Fostec, 2018).

Data, Intelligence, Analytics:

- Big Data: Ability to process data with regard to velocity, variety and volume and gain valuable insights in order to make an informed and reasoned decision (Accenture, 2014);

- Data Analytics: Set of Business Intelligence-Technologies that detects patterns in large sets of data in order to predict future events (Eckerson, 2007).

Human-Machine and Machine-Machine Interaction:

- Virtual/Augmented Reality: Display of additional digital information, e.g. for the employee (Zillmann \& Appel, 2016);

- Manufacturing Technology: New manufacturing technologies (e.g. 3D-printing) for the rapid manufacturing of prototypes or replacement parts (Berman, 2012).

Advanced Procurement:

- Autonomous Transportation: Usage of automated vehicles and transportation systems (on the road as well as in the warehouse) in order to deliver goods more efficiently and increase the driver's productivity (Townsend, 2014);

- Advanced Robotics: Devices that are able to perform different tasks without or with little human intervention or interaction (Deloitte, 2017).

\subsection{Effect of technologies on procurement process}

After the introduction of key procurement steps (sub-section 2.3), cost elements (sub-section 2.4) and technologies (sub-section 3.1) their interdependencies must be highlighted (Table 2).

Table 2. Procurement 4.0-Framework.

\begin{tabular}{|c|c|c|}
\hline Cost Element (Chapter 2.4) & Procurement Step (Chapter 2.3) & 14.0 Technologies (Chapter 3.1) \\
\hline \multirow{2}{*}{ Demand Analysis Costs } & Procurement Strategy & Big Data, Data Analytics, Manufacturing Technologies \\
\hline & Demand Planning & Big Data, Data Analytics, Manufacturing Technologies \\
\hline \multirow{4}{*}{ Supplier Selection Costs } & Offer Request & $\begin{array}{l}\text { Internet of Things, Cloud \& Cyber-Security, Big Data, } \\
\text { Advanced Robotics }\end{array}$ \\
\hline & Offer Evaluation & Data Analytics, Internet of Things, Cloud \& Cyber-Security \\
\hline & Negotiation of Conditions & Big Data, Internet of Things \\
\hline & Supply Agreement & Internet of Things, Cloud \& Cyber-Security \\
\hline \multirow{3}{*}{ Direct Procurement Costs } & Determination of Order Quantity & Data Analytics, Advanced Robotics \\
\hline & Purchase Order & Advanced Robotics, Internet of Things \\
\hline & Material Transport & $\begin{array}{l}\text { Internet of Things, Big Data, Data Analytics, Autonomous } \\
\text { Transportation }\end{array}$ \\
\hline Supplier Failure Recovery Costs, Order Costs & Material Reception and Inspection & $\begin{array}{l}\text { Internet of Things, Virtual/Augmented Reality, Advanced } \\
\text { Robotics }\end{array}$ \\
\hline
\end{tabular}

One of the first decisions an organization has to take when creating the procurement strategy is the make-or-buy decision. With emerging Manufacturing Technologies such as 3D-printing an organization has new opportunities of creating prototypes, spare parts or (semi-) manufactured products (Berman, 2012). Collected Data and Data Analytics support the organization by providing and evaluating data about possible suppliers. Big Data and Data Analytics are also essential for the demand planning process. Especially analytical instruments such as Predictive Analytics can use past data in order to determine nearly optimal demands (Schoenherr \& Speier-Pero 2015). 
For the offer request and offer evaluation the Internet of Things as well as Clouds \& Cyber Security become important. Communication with suppliers and access to shared documents via mobile devices is possible in a decentralized way (Geissbauer et al., 2016). 1deally, the machines that process the material, automatically generate all important data and send them via the Internet of Things to the supplier or share them through Cloud Services (Schlick et al., 2014). Data Analytics become important when evaluating the offer since it is able to compare all received offers with each other as well as data from the past (Schoenherr \& Speier-Pero, 2015).

The opportunity of a decentralized communication through the Internet of Things also has an impact on the negotiations of conditions. Since the offer, that is being negotiated, has already been evaluated through Data Analytics, the organization can use the findings to improve its position in the negotiation (Schoenherr \& Speier-Pero, 2015). Finally, the supply agreement can be transferred through the Internet of Things and provided for all participants in Cloud Services.

The order quantity can be determined and scheduled with the help of Predictive Analytics (Schoenherr \& Speier-Pero, 2015). The usage of stored data and the rate of outgoing inventory are measured by Advanced Robotics in the warehouse to project the ideal order quantity. Finally, the purchase order is made through the Internet of Things, ideally directly by Advanced Robotics on the shop floor or in the warehouse. The material transport can be monitored by shared information about the position or condition of the delivery. By using the data generated on the current route about navigation and traffic, as well as data from the past, Data Analytics can be used to calculate the ideal route concerning time or costs, e.g. for fuel (Waller \& Fawcett, 2013). Once the organization received the material, a notification can be sent to all employees in charge or directly to the machines that can now use this material. If the material needs to be inspected, tools with Virtual or Augmented Reality (e.g. data glasses) help the employee by giving instructions about the handling and the inspection (A.T. Kearney, 2015).

\section{Interrelation between digitization and procurement costs in German industry}

A direct and immediate connection between digitization efforts and the material usage is often assumed. However, there is no proof of this correlation to date. The actual effects of digitization efforts have so far been limited to industrial surveys only. Subsequently, a statistical instrument is used for this purpose that is presented in sub-section 4.1. The results of its application, using time series data from the Federal Statistical Office, are presented in sub-section 4.2. Sub-section 4.3 provides an explanatory approach based on the Procurement 4.0-Framework developed in previous sections.

\subsection{Methodology}

Evidence of the cost-cutting effect of digitization in procurement has so far been unproven. Consequently, the following hypothesis is examined empirically:

$\mathrm{H}_{0}$ := The progress of digitization, measured by machine investments over a certain period as measured by sales, correlates substantially (stronger than -0.5 ) with a reduction in material and commodity expenditures.

This hypothesis is rejected if the calculated coefficients are weak, i. e. less than -0.5 , and therefore no substantial correlation between digitization efforts and procurement costs exists. Moreover, the hypothesis is rejected, if a substantial correlation exists, but is positive.

Therefore, $\mathrm{H}_{1}$ is defined as:

$\mathrm{H}_{1}$ := The progress of digitization, measured by machine investments over a certain period as measured by sales, does not correlate substantially (between -0.5 to 0.5 ) or substantially positive (stronger than 0.5 ) with a reduction in material and commodity expenditures.

The analysis is based on the cost structure of companies in the manufacturing sector in 2015. The selection of branches was made on basis of resource intensity and the importance of the respective branch for the german economy. The relative procurement costs, which are represented by the costs for materials and commodities (based on gross production value), were calculated for those branches. Material consumption includes raw materials and other externally procured intermediate products, auxiliary and operating materials including external components, energy and water, fuels, office and advertising materials as well as non-activated low-value assets. Commodities are deemed to be trading goods which are general unprocessed and without production-technical are resold in combination with their own products (Federal Statistical Office, 2018). 
The relative machine investments (based on the revenue) were used to demonstrate a correlation between procurement costs and investments in digitization. The relative machine investments are regarded as a proxy for the innovation intensity, since investments made after 2011 primarily served digitization.

Since the effect of digitization on procurement goods can vary substantially, a distinction is made between materials and commodities. For this reason, two correlation analyses are conducted per branch. This leads to the reflection of twenty separately calculated correlation coefficients.

For this purpose, the Pearson correlation coefficient is used. It is a measure of the strength of a linear correlation between two variables. In the particular scenario, the degree of correlation between the quantitative characteristics procurement costs and innovation intensity over a period of eight years is determined in order to give an empirically grounded answer to the research question 1 set out in the introduction. A number of key figures can be considered to represent the innovation intensity. Requirements for the parameters used are reliable data availability over a longer period of time and direct attribution to industries in the same period. Research and development expenditure cannot be used as a substitute because, unlike investments in machines, the cost reduction effect does not occur in the same year. Therefore, the relative investments in machines, measured by revenue, were used as a substitute for the digitization efforts of a branch.

Let $\left(x_{i}, y_{i}\right), i=1, \ldots, n$, be the $\mathrm{n}$ observed pairs of values of the bivariate characteristic $(\mathrm{X}, \mathrm{Y})$, then the Pearson correlation coefficient is represented by

$$
r=\frac{s_{x y}}{s_{x} \cdot s_{y}}=\frac{\sum_{i=1}^{n}\left(x_{i}-\bar{x}\right) \cdot\left(y_{i}-\bar{y}\right)}{\sqrt{\sum_{i=1}^{n}\left(x_{i}-\bar{x}\right)^{2} \cdot \sum_{i=1}^{n}\left(y_{i}-\bar{y}\right)^{2}}}
$$

where $s_{x y}$ represents the empirical covariance and $s_{x}, s_{y}$ are the empirical standard deviations of the characteristics $\mathrm{X}$ and $\mathrm{Y}$ in the respective samples. The correlation coefficient has only three important prerequisites that are met in the scenario at hand: linearity of the correlation, finite variance and covariance and a metric scale level (Ahlgren et al., 2003; Rodgers \& Nicewander, 1988).

The dimensionless measure of the degree of linear correlation can vary between -1 and +1 . At a value of +1 (or -1 ) there is a completely positive (or negative) linear relationship between the considered characteristics. If the correlation coefficient has the value 0 , the two characteristics do not depend at all on each other linearly. While the polarity sign of the correlation coefficient determines the direction of linear correlations, its magnitude determines the strength: for values between 0 and 0.5 there is a weak linear correlation, for values between 0.5 and 0.8 a medium linear correlation is present, and for values greater than 0.8 there is a strong linear correlation (Ahlgren et al., 2003; Benesty et al., 2009).

The t-test for checking the correlation coefficients can be used to test whether there is a statistically significant relationship between the characteristic's realizations ${ }^{x_{i}}$ and ${ }^{y_{i}}$. The t-test of the correlation coefficients tests the hypothesis that the correlation coefficient after Pearson is 0 with the intent of rejecting this hypothesis. The specification of $\alpha$ expresses the size of a confidence limit. The confidence interval specifies the range that includes the true parameter position with an infinite repetition of a random experiment with a certain probability (the confidence level). With this test, a statistically reliable statement on the quality of the correlation is provided (Ahlgren et al., 2003; Faul et al., 2009).

The correlations which were subsequently subjected to a t-test, were carried out with the statistics programme SPSS and are presented in sub-section 4.2.

\subsection{Results}

Table 3 presents the Pearson correlation coefficient between innovation intensity in terms of machine investment and the spendings on commodities and material measured as a percentage of revenue. Since a reliable database for the selected industries is limited to eight years, only 12 of the 20 correlation coefficients are significantly different from 0 , according to the t-test. The following interpretation therefore focuses on the significant results without neglecting the remaining results.

The branches can be classified into four main groups:

Group A comprises the branches with a positive correlation between the material costs and the machine investments $\left(\mathrm{H}_{0}\right.$ is rejected), both measured in terms of revenue. This group includes the branches for Chemical Goods, Electrical Equipment, Mechanical Engineering, Motor Vehicles and Components as well as Other Goods. Weak and medium correlations with the majority of highly significant results are in place for the affected industries.

Group B encompasses branches with a negative correlation between the material costs and the machine investments in relation to the share of revenue $\left(\mathrm{H}_{0}\right.$ is confirmed). Thus, it covers the branches Metal Production 
Table 3. Correlation Coefficients between Relative Spendings on Machine Investments and Procurement Costs.

\begin{tabular}{lcc}
\hline \multirow{2}{*}{ Branch } & \multicolumn{2}{c}{ Correlation Coefficient $\boldsymbol{r}$ between Relative spendings on Machine lnvestments and Costs of... } \\
\cline { 2 - 3 } & $\ldots$ Material & ...Commodities \\
\hline Chemical Goods & 0.494 & $-0.899^{* *}$ \\
Pharmaceutical Products & -0.288 & -0.080 \\
Rubber and Plastic Goods & $-0.348^{*}$ & $-0.263^{*}$ \\
Metal Production and Processing & $-0.851^{* *}$ & 0.025 \\
Fabricated Metal Products & $-0.491^{*}$ & 0.061 \\
Electrical Equipment & $0.763^{*}$ & $-0.606^{* *}$ \\
Mechanical Engineering & $0.611^{*}$ & -0.093 \\
Motor Vehicles and Components & $0.748^{* *}$ & $-0.650^{* *}$ \\
Other Transport Equipments & $0.683^{*}$ & 0.124 \\
Other Goods & 0.392 & $-0.508^{* *}$ \\
\hline
\end{tabular}

*significant at the level of $\alpha=0.05$; **significant at the level of $\alpha=0.1$.

and Processing, Fabricated Metal Products and Rubber and Plastic Goods. The involved industries show weak and medium correlations.

Group $\mathrm{C}$ describes the negative correlation between commodities and machine investments expressed as a share of revenue $\left(\mathrm{H}_{0}\right.$ is confirmed). The branches included are Chemical Goods, Rubber and Plastic Goods, Electrical Equipment, Motor Vehicles and Components as well as Other Goods. These industries have medium to strong negative correlations with high significance.

Group D then comprises industries with no substantial linear correlation between the relative expenditures in commodities and machine investments $\left(\mathrm{H}_{0}\right.$ is rejected). This refers to the industries Metal Production and Processing, Fabricated Metal Products, Mechanical Engineering, Other Transport Equipments and Pharmaceutical Products. Therefore, the correlations are weak and not significantly different from 0.

\subsection{Interpretation and explanatory approach}

The results of the correlation analysis show that the distinction between material and commodities is crucial. While there is a distinct effect for commodities, the result of the analysis of material is contradictory. The substantial correlations that have been detected for material and commodities do not describe a causality yet, but the results are explainable via the cost elements in the Procurement 4.0-Framework. Group B and C show correlation coefficients that confirm the hypothesis of cost reduction through digitization.

Organizations, that belong to the branches in Group A show an increase of their procurement cost per unit revenue even though there have been investments into new machines.

In order to explain this result, the cost elements presented in sub-section 2.4 , need to be taken into consideration. Hereby, the influence of technologies on the cost elements, as depicted in Table 2, were analysed:

Due to investments into new machines, the complexity and especially the variety of materials (M) increases since alternative material can be used (Federal Ministry of Education and Research, 2015). This would lead to higher DAC and SSC since the process of the supplier evaluation within the procurement strategy as well as the offer request and evaluation would become more comprehensive. This effect becomes visible especially in Group A. Group B and C are not affected that much. This indicates that for Group B there is no alternative material that can be used and therefore the variety of the material does not increase. Group $C$ is not affected by this circumstance since a different material does not affect the delivery, as long as the commodity meets the requirements.

The increased variety of material, more transparency through the use of Big Data and Data Analytics as well as greater ranges through easier communication through the Internet of Things increase the number of possible suppliers (S) that can be acquired. The SSC increase because of a more complex supplier evaluation. Nevertheless, at the same time, because of the higher competition, purchasing prices of the needed goods decrease, which should decrease the DPC. This effect obviously occurs for organizations in Group B and Group C. However, this effect is partially offset by higher raw material prices. The raw materials, which are used by organizations in Group A, are mostly steel, aluminium and mineral oil. All of these raw materials have an increasing price trend since 2011. This is in contrast to prices for metal and plastics (Boerse Frankfurt, 2018). The price of the raw materials directly affect these organizations. Therefore, DPC does not seem to decrease which also explains the positive correlation detected in Group A. 
A larger number of possible suppliers and improved analytical tools also leads to a lower probability of supplier failure. Nevertheless, the SFC also depend on SSC, that, as mentioned, increase. Organizations in Group A which are affected by increased SSC also face higher SFC.

Digitization increases the efficiency of transports by using Autonomous Transports and Big Data (Waller \& Fawcett, 2013), so that the cost for placing one order is reduced. As the variety of materials $M$ increases, the demand $\mathrm{d}$ for individual material types is reduced. This results in a reduction of OC.

The remarks explain the results of the correlation analysis and show that digitization in some branches (Group B and Group C) leads to lower procurement costs. However, the results for Group A also show that the ideal effect does not apply in all branches. In these branches, the arising expenses exceed the cost savings of digitization.

For the organizations that belong to Group D no significant correlation was detected. This can be justified by the small ratio of procurement costs on the GPV (sub-section 2.2).

\section{Conclusion and Outlook}

Procurement costs are the central lever for increasing the economic viability of companies. These procurement costs were divided into material costs and commodity costs. Material costs are of greater importance across all industries and show a negative trend over almost a decade. Based on the procurement process, five central cost elements were derived and combined with the Procurement 4.0-Technologies to establish a Procurement 4.0-Framework. The empirical examination of the correlation between digitization efforts and procurement costs shows predominantly significant results and emphasises the importance of distinguishing between material costs and commodity costs. On the one hand, the results show the expected negative correlation, which confirms the hypothesis of cost reduction through digitization. On the other hand, there are positive correlations for some industries. The results are plausibly explained using the Procurement 4.0-Framework.

The linear correlation between simultaneously measured values of two different characteristics was examined. However, since the cost-cutting effect of digitization can also be achieved with a delay of several years, the correlation between different measurement values with different time periods has to be examined. In addition, only the relative investments for one year were considered. It would also make sense to consider cumulative investments in machines and equipment. A separate analysis of the cost trends before and after the announcement of the fourth industrial revolution in 2011 seems meaningful in the light of our results. As soon as a sufficient database for a time series analysis after 2011 is available, this study should be repeated.

With the Procurement 4.0-Framework, a frequently assumed cause-and-effect relationship between digitization and procurement costs is systematically considered for the first time. The Procurement 4.0-Framework provides an explanation for the significant correlations. Although this framework is an explanatory approach for this statistical context, it has not itself undergone statistical testing. In addition, the conclusions based on this macroeconomic and cross-sectoral analysis provide an initial indication of a fundamental relationship, but require technological and sector-specific substantiation. The costs associated with the investment in machines may also include costs that are not related to digitization. A decomposition of the machine investments is possible through stronger operational data.

This empirical examination as well as the explanatory approach are key supplements to the previous survey-based studies on the effect of digitization on procurement costs.

\section{References}

A.T. Kearney. (2015). Digital supply chains: increasingly critical for competitive edge. A.T. Kearney.

Accenture. (2014). Global operations megatrend study: big data analytics in supply chain: hype or here to stay? Canada. Retrieved in 7 December 2018, from https://www.accenture.com/t20160106T194441_w__fi-en/_acnmedia/Accenture/Conversion-Assets/DotCom/ Documents/Global/PDF/Digital_1/ Accenture-Global-Operations-Megatrends-Study-Big-Data-Analytics-v2.pdf

Ahlgren, P., Jarneving, B., \& Rousseau, R. (2003). Requirements for a cocitation similarity measure, with special reference to Pearson's correlation coefficient. Journal of the American Society for Information Science and Technology, 54, 550-560.

Aisbett, J., Lasch, R., \& Pires, G. (2005). A decision-making framework for adoption of e-procurement. International Journal of Integrated Supply Management, 1(3), 278-293.

Andriolo, A., Battini, D., Grubbström, R. W., Persona, A., \& Sgarbossa, F. (2014). A century of evolution from Harris's basic lot size model: survey and research agenda. International Journal of Production Economics, 155, 16-38.

Arnold, U. (1997). Beschaffungsmanagement. Stuttgart: Schäffer-Poeschel Verlag.

Arnolds, H., Heege, F., Röh, C., \& Tussing, W. (2013). Materialwirtschaft und Einkauf(12th ed.). Wiesbaden: Springer Gabler.

Bauer, W., Schlund, S., Marrenbach, D., \& Ganschar, O. (2014). Industrie 4.0: Volkswirtschaftliches Potenzial für Deutschland. Berlin: BITKOM.

Benesty, J., Chen, J., Huang, Y., \& Cohen, I. (2009). Pearson correlation coefficient. In J. Benesty, J. Chen, Y. Huang \& 1. Cohen (Eds.), Noise reduction in speech processing (Springer Topics in Signal Processing, No. 2, pp. 1-4). Berlin: Springer. 
Berman, B. (2012). 3-D printing: the new industrial revolution. Business Horizons, 55(2), 155-162.

Boerse Frankfurt. (2018). Rohstoffe. Retrieved in 7 December 2018, from http://www.boerse-frankfurt.de/rohstoffe

Botthof, A. (2015). Zukunft der Arbeit im Kontext von Automatik und Industrie 4.0. In A. Botthof \& E. A. Hartmann (Eds.), Zukunft der arbeit in industrie 4.0 (pp. 3-8). Berlin: Springer.

Daimler AG. (2016). Jahresabschluss 2016 der Daimler AG. Stuttgart.

Deloitte. (2017). Using autonomous robots to drive supply chain innovations. Retrieved in 7 December 2018, from https://www2.deloitte. com/content/dam/Deloitte/us/Documents/manufacturing/us-manufacturing-autonomous-robots-supply-chain-innovation.pdf

Drath, R. (2014). Industrie 4.0. Eine Einführung. Open Automation, 3, 2-7.

Eckerson, W. W. (2007). Predictive analytics: extending the value of your data warehousing investment. Renton: TDW1 Research.

Faul, F., Erdfelder, E., Buchner, A., \& Lang, A. G. (2009). Statistical power analysis using G*Power 3.1: test for correlation and regression analysis. Behavior Research Methods, 41(4), 1149-1160. PMid:19897823.

Federal Ministry of Education and Research - BMBF. (2015). Vom Material zur Innovation. Bonn: BMBF.

Federal Statistical Office. (2018). Kostenstruktur der Unternehmen im verarbeitenden Gewerbe: Deutschland, Jahre, Wirtschaftszweige (2-/3-/4-Steller). Retrieved in 7 December 2018, from https://www-genesis.destatis.de/genesis/online/data;jsessionid=23549AE70D 68B6F28833CAB885993CE6.tomcat_G0_2_2?operation=abruftabelleAbrufen\&selectionname=42251-0004\&levelindex=1\&levelid= $1515165354471 \&$ index $=4$

Fostec. (2018). Industrie 4.0. Retrieved in 7 December 2018, from https://www.fostec.com/de/kompetenzen/digitalisierungs-strategie/ industrie-4-0/

Foster, G., \& Gupta, M. (1990). Manufacturing overhead cost driver analysis. Journal of Accounting and Economics, 12, 309-337.

Geissbauer, R., Weissbarth, R., \& Wetzstein, J. (2016). Procurement 4.0: are you ready for the digital revolution? United States: Strategy\&, PwC.

Glas, A. H., \& Kleemann, F. C. (2016). The impact of industry 4.0 on procurement and supply management: a conceptual and qualitative analysis. International Journal of Business and Management Invention, 6(5), 55-66.

Grochla, E., \& Schönbohm, P. (1980). Beschaffung in der Unternehmung. Stuttgart: Poeschel.

Hütter, S.H. (2007). Beschaffungskosten und eProcurement. Lohmar: Josef Eul Verlag.

Kagermann, H. (2015). Change through digitization: value creation in the age of industry 4.0. In H. Albach, H. Meffert, A. Pinkwart \& R. Reichwald (Eds.), Management of permanent change (pp. 23-45). Wiesbaden: Springer Gabler.

Kagermann, H., Wahlster, W., \& Helbig, J. (2012). Umsetzungsempfehlung für das Zukunftsprojekt Industrie 4.0: Abschluss des Arbeitskreises Industrie 4.0. Berlin: Acatech.

Kiel, D., Arnold, C., \& Voigt, K.-l. (2017). The influence of the industrial internet of things in business models of established manufacturing companies: a business level perspective. Technovation, 68, 4-19.

Koehler, P., Six, B., \& Michels, J. S. (2015). Industrie 4.0: Ein Überblick. In C. Koehler-Schute (Ed.), Industrie 4.0: Ein praxisorientierter Ansatz (pp. 17-39). Berlin: KS-Energy.

Kovatsch, M., Mayer, S., \& Ostermaier, B. (2012). Moving application logic from the firmware to the cloud. In Proceedings of the 6th International Conference on Innovative Mobile and Internet Services in Ubiquitous Computing (IMIS) (pp. 751-756). Washington: IEEE Computer Society.

Krampf, P. (2014). Beschaffungsmanagement (2nd ed.). München: Vahlen.

Kummer, S., Grün, O., \& Jammernegg, W. (2013). Grundzüge der Beschaffung, Produktion und Logistik (3rd ed.). München: Pearson.

Lasi, H., Fettke, P., Feld, T., \& Hoffmann, M. (2014). Industry 4.0. Business \& Information Systems Engineering, 4, $239-242$.

Lee, H., Padmanabhan, V., \& Whang, S. (1997). The bullwhip effect in supply chains. Sloan Management Review, 38(3), 93-102.

Melzer-Ridinger, R. (2008). Materialwirtschaft und Einkauf(5th ed.). München: Oldenbourg.

Möllering, G., Behar, B., \& Sommer, F. (2005). Strategische Beschaffung in hybriden Organisationsformen. WiSt. Wirtschaftswissenschaftliches Studium, 34(6), 315-320.

PricewaterhouseCoopers - PwC. (2014). Industrie 4.0: Chancen und Herausforderungen der vierten industriellen Revolution. Munich: GRIN Verlag.

Rodgers, J. L., \& Nicewander, W. A. (1988). Thirteen ways to look at the correlation coefficient. The American Statistician, 42(1), 59-66.

Schlick, J., Stephan, P., Loskyll, M., \& Lappe, D. (2014). Industrie 4.0 in der praktischen Anwendung. In T. Bauernhansl, M. ten Hompel \& B. Vogel-Heuser (Eds.), Industrie 4.0 in Produktion, Automatisierung und Logistik: Anwendung, Technologien, Migration (pp. 57-84). Wiesbaden: Springer.

Schmidt, R., Möhring, M., Härtling, R.-C., Reichstein, C., Neimaier, P., \& Jozinovic, P. (2015). Potentials for creating smart products: empirical research results. In W. Abramowicz (Ed.), Business information systems (pp. 16-27). Cham: Springer.

Schoenherr, T., \& Speier-Pero, C. (2015). Data science, predictive analytics, and big data in supply chain management: current state and future potential. Journal of Business Logistics, 36(1), 120-132.

Steven, M. (2013). Einführung in die Produktionswirtschaft. Stuttgart: Kohlhammer.

Steven, M., \& Klünder, T. (2018). Nachhaltigkeit schlanker Industrie 4.0-Netzwerke. ln A. Khare, D. Kessler \& J. Wirsam (Eds.), Marktorientiertes Produkt- und Produktionsmanagement in digitalen Umwelten (pp. 201-221). Wiesbaden: Springer Gabler.

Theisen, P. (1974). Beschaffung und Beschaffungslehre. In E. Grochla \& W. Wittmann (Eds.), Handwörterbuch der Betriebswirtschaft (pp. 494-503). Stuttgart: Springer.

Townsend, A. (2014). Re-programming mobility. New York: NYU Wagner.

Waller, M. A., \& Fawcett, S. (2013). Data science, predictive analytics, and big data: a revolution that will transform supply chain design and management. Journal of Business Logistics, 34(2), 77-84.

Zillmann, M. \& Appel, B. (2016). Keine Industrie 4.0 ohne Digitalisierung der Supply Chain. Mindelheim: Lünendonk. 